\title{
Design and implementation of fresh food micro marketing model -- a case study of WeChat toon
}

\author{
Sun Ruonan, Jin Xinlei, Zhang Na*, Shan Juanjuan, Xu Jian \\ College of Computer and Information Engineering \\ Beijing University of Agriculture \\ Beijing, China \\ 597369409@qq.com
}

\begin{abstract}
With the development of mobile Internet and the increase of the Wechat users, using Wechat and other new media technology in the marketing of agricultural products has become an important form of marketing. However, fresh food with a short shelf life, difficult logistics and other characteristics, the main sales channel is the farmers markets, supermarkets and other physical stores. Therefore, how to take advantage of this new marketing micro-marketing model to achieve rapid sales of fresh food has become an issue to improve the efficiency of fresh food marketing must face. Analyzing the new media marketing model and the marketing difficulties of fresh food, take the Mentougou Sijiashui Chinese toon as an example, take advantage of new media means to achieve the design and implementation of micro-marketing model, increase sales of fresh food of the mountains area.
\end{abstract} model

Keywords—new media; micro marketing; fresh food; WeChat;

\section{INTRODUCTION}

With the rapid progress and application of Internet technology, in recent years, The rapid development of the new communication platform with the mobile Internet and micro blog, micro channel and micro film as the representatives. The characteristics of "precise, interactive, open, fast, convenient," make the pattern of the new meida change. And e-commerce O2O (Online To Offline) 、 micro applications and other means make the people's original way of experience changed, and then a new marketing method - micro marketing also generates [1]. "Micro era" is coming, modern enterprises have begun to use micro marketing to carry out product sales.

Fruits and vegetables, meat, aquatic products are three kinds of reprensentative food of fresh food. Due to limitations of logistics difficulties, short preservation time and other characteristics of fresh food, it's sales channels are mainly farmers markets, supermarkets and other physical stores. But in recent years, with the rapid development of innovative logistics and the innovation of cold chain technology, fresh food break the traditional marketing model, began to enter the new marketing model. Faced with the existing marketing structure and in the context of new information dissemination, research on micro marketing of fresh food, which is of great significance in expanding its market, improve sales efficiency.

\section{NEW MEDIA MARKETING MODE ANALYSIS}

\section{1. "Micro marketing" and "WeChat"}

Micro marketing is the combination of traditional marketing and modern network marketing. On the basis of the transformation of the marketing strategy ,It Combine the traditional way with the Internet thinking mode and based on the mobile Internet as the main platform, establish and strengthen customer relationship through enterprise marketing planning, brand planning, operation planning, sales methods and strategies to achieve new breakthroughs in marketing. The main mode of marketing is the marketing body carry out the information of the product release, display and promotion, customer interaction and theme activities, etc through the network interactive platform. Lead customers to participate actively, and finally realize the marketing goal [2]. Micro marketing does not mean WeChat marketing, WeChat marketing is a component of micro marketing. Micro-blog, WeChat, micro film portfolio is not a micro marketing, they are the main form of micro marketing.

WeChat includes WeChat's personal account and WeChat public platform. Personal account support chat (send voice messages, video, pictures and text), add friends, real-time intercom, friends circle, WeChat group, and other basic functions. Public platform mainly has the function of real time communication, message sending and material management.

At present, the development of WeChat's is not just a mobile phone application full of innovative features, It has become the representative of China's electronic revolution, covering more than $90 \%$ of the smart phone, and become an indispensable tool for daily use in people's lives. According to the 2015 released Tencent micro credit user data report, by the end of the first quarter of 2015, micro channel monthly active users has reached 5.49 billion, the brand micro channel public account has a total of more than 800 million, WeChat paid subscribers reached about 400 million and micro channel directly driven life consumption scale has reached 110 billion . 
Visible, WeChat platform user traffic is sufficient for the micro marketing of fresh products provides a huge potential customer base. The arrival of the mobile Internet era, providing the possibility of micro marketing, it eliminates the limitations of time and space, allowing users to make full use of the fragmentation time, to achieve anytime, anywhere shopping [3].

\section{Technical environment}

Market research firm Nelson released the "2013 mobile consumer reports" show that China's smart phone penetration rate of $66 \%$, has surpassed the United States and the United Kingdom's penetration rate, but after living in South korea. With the smart phone in the market share of the upgrade, WeChat, micro-blog applications on the mobile phone with the corresponding rate also has significantly improved. Moreover, young people are the main consumer groups of Smart phones as well as pay for consumption by mobile phone Alipay and WeChat. Therefore, the young people have become the new marketing model of the main consumer groups. Visible, the popularity of smart phones provides a favorable technical environment for the micro marketing of fresh food, but also for the marketing of fresh food enough to reach the target population.

With the increasing number of users of the Micro-blog, WeChat, The microblogging, micro channel, micro film three is to achieve interoperability, Micro-blog articles can be forwarded to a key to WeChat circle of friends, WeChat circle of friends can also be forwarded to each other, micro-blog, WeChat can also be uploaded to the micro movie, the three Micro achieve data sharing based on the internet. This communication in the circle of friends has played a communication effect, directly and effectively enhance the brand communication force, which is often mentioned in our social media word-of-mouth marketing, As long as there is something of value, users will not be stingy and friends to share, but also makes the relationship marketing is widely spread[4]. The three kinds of application software, most users are used at the same time, three the continuous improvement of micro function provides a wide range of consumer groups for the use of fresh food micro marketing.

\section{Technical environment Social and cultural environment}

With the improvement of social economy and the usage of "Three micro" (WeChat, micro-blog, Micro video), micro propagation is much faster than the original. And slowly it replaces the traditional telephone, radio, and other means of transmission. The current social atmosphere mainly spreads things, catharsis mood, comments on social phenomenon through the micro-blog, WeChat and so on. With the development of micro era, their influence on social communication will not be underestimated.

\section{THE DESIGN AND REALIZATION OF THE MICRO MARKETING MODE OF FRESH FOOD}

Now I will take Sijiashui red Chinese toon for example to introduce the design and realization of the micro marketing mode of fresh food.

\section{The design of Chines toon's micro marketing mode}

WeChat public number of Sijiashui red Chinese toon set up 3 Fist-level plates, 12 Two-level plates. The 3 Fist-level plates are "Chinese toon introduction”,” Peripheral Tour”, and "Micro Services". The fist plate includes "toon resume” ,“certified organic”, ” landmarks”, ” Toon delicacy " and " toon secret". The second plate includes "First party branch of Jingxi”,” Weizishui ancient villages”, “Temple silt in vain waterfall”, and "Tiansheng Lake Reservoir". The third plate includes "map navigation", "Weather forecast" and "Contact us". The following detailed description is of specific settings on each plate.

\subsection{Chinese toon introduction}

This section is mainly to do a detailed introduction to the basic situation of Chinese toon.

Chinese toon resume: To introduce the history of SiJiashui red Chinese toon, growth environment, production control, variety selection, nutrition and medicinal content in the form of pictures and texts.

Organic certification, landmarks: Sijiashui red Chinese toons are the national agricultural products of geographical indications protection products, and its geographical indication registration certificate and organic certification will be show, accompanied with words.

Toon delicacy: a simple recipe of Chinese toon.

Toon secret: Chinese toon is delicious, but it contains nitrite. So I show the precautions of edible Chinese toon to remind the vast number of consumers.

\subsection{Peripheral Tour}

Sijiashui is located in Mentougou District, Peking City, Yanchi Town. In order to attract more consumers to buy Chinese toon, I will introduce attractions near Sijiashui. And expand the toon visibility, purchase.This section mainly introduces "First party branch of Jingxi”,"Weizishui ancient villages", "Temple silt in vain waterfall", and "Tiansheng Lake Reservoir” by words and pictures.

\subsection{Micro Services}

The theme of this plate is service. Under the plate, there set "map navigation", "Weather forecast" and "Contact us". It is more convenient for consumers to go to Sijiashui.

\section{The micro marketing mode of Chinese toon}

\subsection{Registered public platform}

WeChat public platform uses the mailbox registering, selects the public account type for the subscription number and the main body for the organization, fills in the relevant information, uploads the relevant certification and applies for certification to wait for the audit. After approval, we begin to custom menus, to edit the WeChat public account and to make the public number named "Tingmei Tian Zhuang Gou". In the end, we set add automatic reply and key words reply function. 
After user attention, enter the WeChat public interface as shown in figure 1.
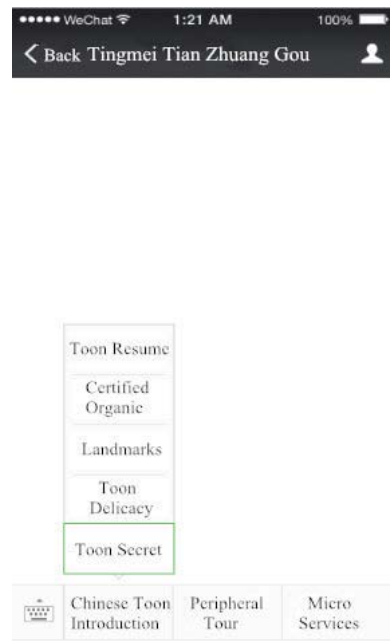

Fig. 1. Toon Wechat public number home.

\subsection{Design two-dimensional code publicity}

Two-dimensional code which is developed by Tencent Inc to cooperation with WeChat is a new way to find and add a friend We design a unique the two-dimensional code name card design for red Chinese toon of Sijiashui in order to make users identify the two-dimensional code to concern the public account.In the rapid development of the Internet today, the two-dimensional code is a business card on the internet. users focus on their own through the two-dimensional code, promote the visibility of the enterprise and enhance publicity effect of red Chinese toon of Sijiashui.

\subsection{Mass message promotion}

Subscription number can push a messageall to all users every day, the push message types include: 600 words within the text, images, audio, video. It also can push graphic messages, including single graphic news and graphic messages. Red Chinese toon of Sijiashui get a promotion by the function of push message. Push messages can also forwarded in the circle of friends. It can enhance the consumer's memory of red Chinese toon of Sijiashui and broad the customer network. Push messages for example shown in figure 2 .

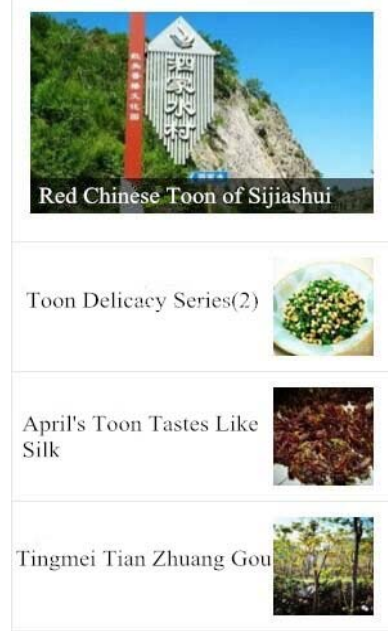

Fig. 2. Toon Wechat public number push message.

\section{SUMMARY}

Using micro channel platform for Sijiashui red Chinese toon developed WeChat public number and increased sales of Chinese toon and achieve the promotion of mobile and the effect of informatization. At present, "Tingmei Tian Zhuang Gou" WeChat public number one has been on the line, the use of "circle of friends", “WeChat public platform”, under the premise of safety and quality guarantee of Chinese toon, Sijiashui red Chinese toon to create micro marketing brand. WeChat public number two will use the development model, to achieve WeChat buy, WeChat payment and other functions.

\section{References}

[1] Zhang Guobin,Xiao Yuxiu, “On micro marketing strategy of small and medium sized farmers' agricultural products”. Modern agricultural science and technology, vol. 24, pp. 342-343, 2014.

[2] Xiao Xiao. "Enterprise micro marketing in the new media era”.Economic Vision, vol. 6, pp. 134-135, 2014.

[3] Xi Chao,Tan Shujuan,Wang Yuan,Zhao Mei. “The practice of micro marketing of agricultural products with special characteristics in Yunnan Plateau”. Modern agricultural science and technology, vol. 14, pp. 350352, 2014.

[4] Yan Haiping. "Beautiful said micro marketing strategy analysis”.Culture Orporate, vol. 3, pp. 183-184, 2014.

[5] Li Lihua,Wu Xinling. "Micro marketing strategy analysis of aging brands in micro Era”.Modern Business, pp. 51-52, 2014. 